Research article

\title{
In Vitro antioxidant, antibacterial and phytochemical screening of Cochlospermum religiosum (L.) Alston - A potent medicinal plant
}

\author{
Pooja Ponnamma, G. Manasa, M. S. Sudarshana, M. Murali and C. Mahendra*
}

University of Mysore, Department of Studies in Botany, Manasagangotri, Mysore-570006, Karnataka, India

*Corresponding Author: mahendra.c149@gmail.com

[Accepted: 12 January 2017]

\begin{abstract}
The work is undertaken to evaluate the preliminary phytochemicals, antibacterial and antioxidants activity of Cochlospermum religiosum leaf extracts with three solvents via chloroform, ethyl acetate and methanol based on polarity index. The antibacterial activity was assessed against five bacterial pathogens like Escherichia coli, Bacillus subtilis, Bacillus cereus, Staphylococcus aureus and Pseudomonas aeruginosa by well diffusion assay. Among the tested pathogens, the maximum zone of inhibition was observed against $E$. coli $(26 \mathrm{~mm})$ followed by $P$. aeruginosa $(23 \mathrm{~mm})$ in ethyl acetate extracts compare to other solvent extracts. Phytochemical analysis also revealed the presence of various pharmaceutically active secondary metabolites like alkaloids, phenolic, flavonoids, saponins, carbohydrates, proteins, glycosides, sterols, etc. Antioxidant activity was determined by DPPH scavenging, total phenolic and phosphomolybdenum method. In DPPH assay, ethyl acetate extract was found to be the most effective. Similarly, total phenols and phospho-molybdenum assay the methanol extracts was found to contained good sources of antioxidants. The outcomes of the present study specified the plant possess various potentially active secondary metabolites which help for the developing pharmaceuticals, especially antioxidant and antimicrobial drugs.
\end{abstract}

Keywords: Cochlospermum religiosum, Phytochemical, Antibacterial, Antioxidants, DPPH.

[Cite as: Ponnamma P, Manasa G, Sudarshana MS, Murali M \& Mahendra C (2017) In Vitro antioxidant, antibacterial and phytochemical screening of Cochlospermum religiosum (L.) Alston - A potent medicinal plant. Tropical Plant Research 4(1): 13-19]

\section{INTRODUCTION}

Nature has been a source of medicinal agents for thousands of years and by using the natural resources impressive number of the drugs have been isolated. Most of these isolations commonly based on their uses in traditional medicine (Cragg \& Newman 2001). More than $65 \%$ of the global population uses medicinal plants as a primary health care modality. The medicinal plants are useful for healing and as well for curing human diseases because of the presence of phytochemical constituents (Fabricant \& Farnsworth 2001). Phytochemicals are naturally occurring compounds in medicinal plants which have defense mechanism and protect various diseases (Motaleb 2011). In recent years natural antibiotics have been used for several infectious diseases, regarding to this, the work on new antimicrobial agents from plants are even more essential especially in the countries like India where infectious diseases of bacteria are not only rapid but are also more resistant to common antibiotics (Shah et al. 2014). Most of the medicinal plants holding active secondary metabolites with high antioxidant property which are playing important role in the prevention of various diseases (Lobo et al. 2010). Natural antioxidants from plant sources are potent and safe due to their harmless nature.

Cochlospermum religiosum (L.) Alston is a small sparsely branched tree belonging to family Bixaceae. It is commonly called yellow silk cotton tree, butter cup tree, and torch wood tree because of flowers are large, bright golden yellow and seeds are covered with silky hairs (Sasikala et al. 2013). The name of the tree "Religiosum" derived from the fact that the flowers are used for temple offerings. The plant can easily identify by its characteristic feature of deeply furrowed bark, lobed leaves and bright golden yellow bisexual flowers. 
The tree especially known for its gum- yielding character, the gum is orange in color which exudes from the bark. The gum is medicinally used for the treatment of stomachic, sedative, gonorrhea, syphilis and asthma (Pandhure et al. 2013). Hence the attempt has been made in this study to examine various phytochemical constituents, and their antibacterial and antioxidant efficacy of various solvent extracts of C. religiosum.

\section{MATERIALS AND METHODOLOGY}

Plant material collection

The fresh leaves of Cochlospermum religiosum (L.) Alston was collected from Chamundi Hills, Mysuru and identified with the help of Flora of Presidency of Madras (Gamble 1935) healthy leaves were separated then washed with running tap water, and then cut into small pieces and shade dried at room temperature until it is complete gets dried.

\section{Preparation of plant extract}

Dried leaf powder was extracted in three different solvents like chloroform, ethyl acetate and methanol $30 \mathrm{~g}$ of plant powder extracted in $300 \mathrm{ml}$ of solvents for $24 \mathrm{hrs}$ in a rotary shaker at room temperature. The supernatant was collected and evaporated to get extracts and same procedure was followed to remaining solvents and obtained crude extracts was stored at $4^{\circ} \mathrm{C}$ in air tight glass bottles for further studies (Maizura et al. 2011)

\section{Phytochemical Analysis}

The dried powdered plant material was extracted sequentially with solvents, viz., Chloroform, Ethyl acetate and methanol based on polarity index. The obtained solvent extracts were subjected to qualitative phytochemical screening to detect the presence of various phytoconstituents like Carbohydrates, Alkaloids, Glycosides, Sterols, Flavonoids, Saponins, Triterpenes, Resins and Proteins followed by the standard procedure given by Harborne (1972).

\section{Antibacterial activity}

i. Test micro-organisms:

Bacterial cultures were procured from Microbial Type Culture Collection and Gene bank (IMTECH, Chandigarh, India). The antibacterial activity was carried out against both Gram positive and Gram negative bacteria viz. Gram-positive (Staphylococcus aureus MTCC - 7443 and Bacillus subtilis (MTCC -121) Gramnegative (Escherichia MTCC -7410 and Pseudomonas aeruginosa MTCC -1688).

\section{ii. Agar-well Diffusion Method:}

The antibacterial activity was determined by agar well diffusion method. Nutrient agar plates were swabbed with $24 \mathrm{hrs}$. old culture of selected bacteria. $10 \mathrm{~mm}$ wells were made in each NA plates using sterile cork borer. Standard and Stock solution of leaf extract was prepared at the concentration of $100 \mathrm{mg} . \mathrm{ml}^{-1}$ of each extracts. About different concentrations of plant extracts 25,50 and $75 \mu l$ were added to the wells by using micro pipettes and allow to diffusing at room temperature for 2 hours. The plates were incubated at $37^{\circ} \mathrm{C}$ for $24 \mathrm{hrs}$. The diameter of inhibition zone was measured in millimeter (Antarasen et al. 2012).

\section{Antioxidant assay}

\section{i. DPPH Free radical scavenging activity assay:}

DPPH free radical scavenging activity was performed as described by Abdulwahab et al. (2011) and Mahendra et al. (2016). Briefly $1 \mathrm{ml}$ of leaf extracts and the standard solution of Gallic acid from 8 different concentrations of the absolute methanol were added to $4 \mathrm{ml}$ of DPPH reagent in 8 test tubes. DPPH and absolute methanol were used for reagent blank. All reagents were mixed and incubated for 30 minutes at room temperature, protected from light. The absorbance was measured at $517 \mathrm{~nm}$ by using a spectrophotometer. Experiments were done in triplicates. The percentages of the DPPH free radical scavenging activity were calculated as follows:

$$
\% \text { scavenging activity }=\frac{A b s(\text { control })-A b s(\text { sample })}{A b s(\text { control })} X 100
$$

\section{ii. Estimation of total phenolic content:}

Total phenolics in the leaf extract of plant were determined using the Folin - Ciocalteu reagent method (Chlopicka et al. 2012). A stock solution of leaf extracts was prepared to the concentration of $1 \mathrm{mg} \cdot \mathrm{ml}^{-1}$. To 1 $\mathrm{mL}$ of each extract, $5 \mathrm{mg} \cdot \mathrm{ml}^{-1}$ of FC Reagent were added. The mixture of solution was vortexed and incubated 
in the dark chamber for $3 \mathrm{~min}$, respectively. After that $5 \mathrm{mg} \cdot \mathrm{ml}^{-1}$ of sodium carbonate $\left(75 \mathrm{~g} . \mathrm{l}^{-1}\right)$ solution was added to the mixture and mixed thoroughly. The mixture was again incubated in the dark for $1 \mathrm{hr}$. The absorbance was read at $765 \mathrm{~nm}$. Blank consisted of $5 \mathrm{mg} \cdot \mathrm{ml}^{-1}$ FC reagent, $1 \mathrm{~mL}$ ethanol, and $4 \mathrm{~mL}$ sodium carbonate solution.

iii. Phospho - molybdate assay:

The total antioxidant capacity of the extracts was determined by phospho - molybdate method by using Gallic acid as standard. An aliquot of $0.1 \mathrm{ml}$ of the sample solution was mixed with $1 \mathrm{ml}$ of reagent solution. The tubes were incubated in a water bath at $95^{\circ} \mathrm{C}$ for 90 minutes. After the samples had cooled to room temperature, the absorbance of a mixture of the sample was measured at $765 \mathrm{~nm}$ against a blank. A typical blank contains $1 \mathrm{ml}$ of reagent solution and the appropriate volume of the solvent was incubated under the same conditions.

\section{RESULTS}

\section{Phytochemical Screening}

The preliminary phytochemical screening of $C$. religiosum leaf crude extracts of various solvents showed the presence of secondary metabolites like alkaloids, steroids, flavonoids, terpenoids, glycosides, carbohydrates, tannins, saponins and phenols and the results were tabulated in the (Table 1). Among the tested extract, ethyl acetate was showed maximum phytochemicals followed by methanol extracts and sterols, triterpenes and flavonoids were absent in both ethyl acetate and chloroform extracts and present in methanol extracts.

Table 1. Preliminary Phytochemical screening of Cochlospermum religiosum.

\begin{tabular}{|c|c|c|c|c|}
\hline \multicolumn{2}{|c|}{ Phytochemical Tests } & \multirow{2}{*}{$\begin{array}{c}\text { Chloroform } \\
-\end{array}$} & \multirow{2}{*}{$\begin{array}{c}\text { Methanol } \\
+\end{array}$} & \multirow{2}{*}{$\begin{array}{c}\text { Ethyl acetate } \\
-\end{array}$} \\
\hline Sterols & Salkowski Test & & & \\
\hline \multirow{3}{*}{ Triterpenes } & Liebermann-Burchard Test & - & + & - \\
\hline & Salkowski Test & - & + & - \\
\hline & Liebermann-Burchard Test & - & + & - \\
\hline Saponins & Foam test & - & + & - \\
\hline \multirow[t]{4}{*}{ Alkaloids } & Mayer's Test & - & - & + \\
\hline & Dragendroff's Test & + & - & + \\
\hline & Wagner sTest & + & - & + \\
\hline & Hagers Test & + & - & + \\
\hline \multirow[t]{2}{*}{ Tannins } & $\mathrm{FeCl}_{3}$ Test & + & - & - \\
\hline & GelatinTest & + & - & - \\
\hline \multirow[t]{3}{*}{ Flavonoids } & Shinado Test & - & + & - \\
\hline & $\mathrm{FeCl}_{3}$ Test & - & + & - \\
\hline & Lead acetate test: & - & + & - \\
\hline \multirow[t]{3}{*}{ Carbohydrates } & Molisch's & - & + & - \\
\hline & Fehling's Test & + & + & - \\
\hline & Benedicts Test & - & + & - \\
\hline Phenols & FC reagent test & + & + & + \\
\hline \multirow[t]{2}{*}{ Proteins } & Biuret Test & - & - & - \\
\hline & Ninhydrin Test & - & - & - \\
\hline Glycosides & Keller killiani test & + & - & - \\
\hline
\end{tabular}

Note: "+"= Present "“"= Absent

\section{Antibacterial activity}

The results of antibacterial activity studies was performed by agar well diffusion assay by using crude chloroform, ethyl acetate, and methanol solvent extracts of leaf parts of $C$. religiosum analyzed against 5 different gram positive and gram negative human pathogenic bacteria with compared standard antibiotic streptomycin. It was found that the maximum zone of inhibition was observed in ethyl acetate extract which was most effective against $E$. coli $(26 \pm 0.27)$ and $P$. aeruginosa $(23 \pm 0.35)$ followed by B. cereus $(18 \pm 0.43)$, Bacillus subtilis $(17 \pm 0.24)$ and Staphylococcus aureus $(14 \pm 0.10)$ compare to chloroform and methanol extracts. It was also noticed that the bactericidal properties of the treated crude extracts was concentration dependent which gives higher zone of inhibition with increasing the concentration and the results are presented in (Table 2, Fig. 1). 

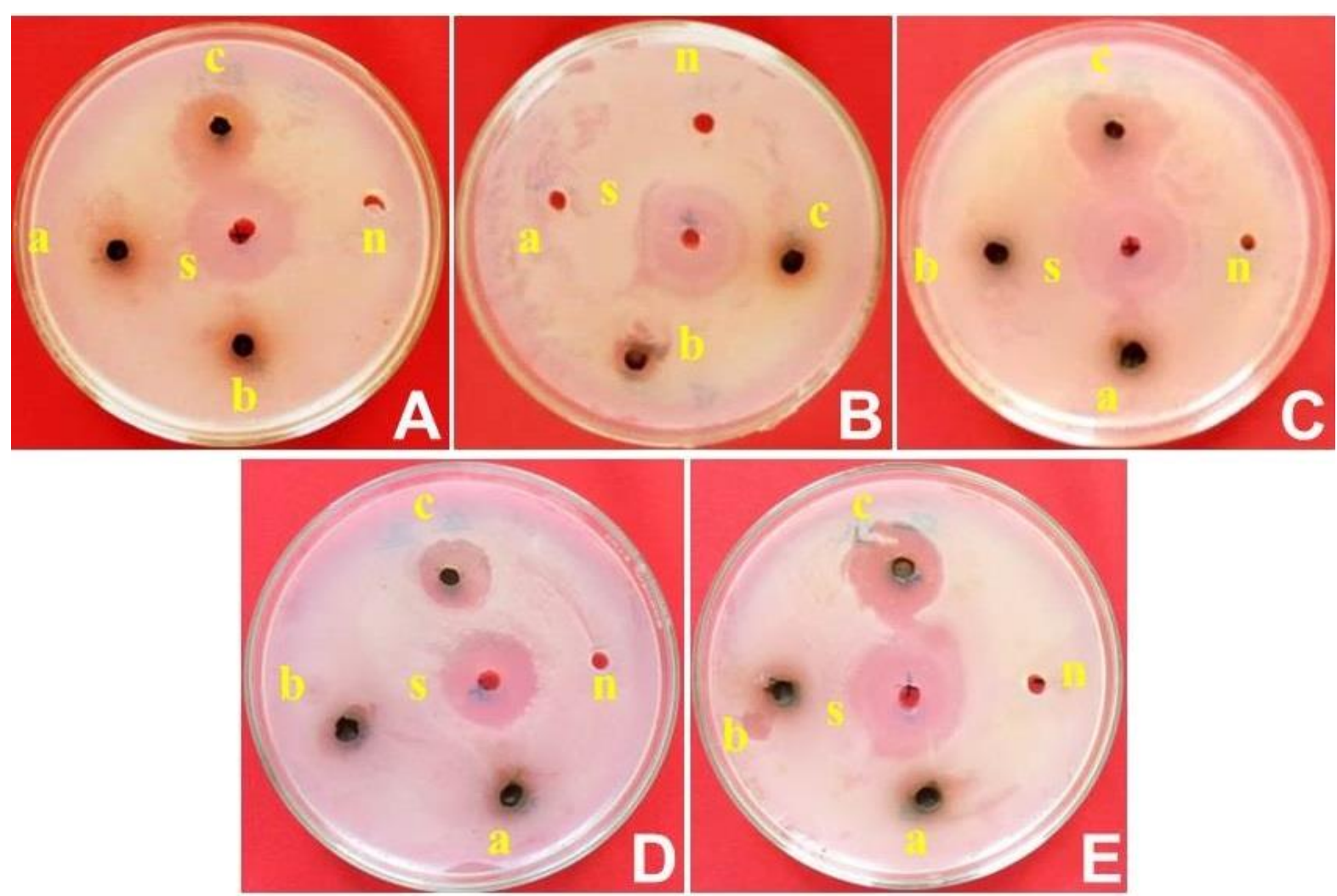

Figure 1. Ethyl acetate leaf extract of Cochlospermum religiosum against different strains of bacteria: A, Bacillus cereus; B, Bacillus subtilis; C, Pseudomonas aeruginosa; D, Staphylococcus aureus; E, Escherichia coli (Scale: a, $25 \mu \mathrm{l} ; \mathrm{b}, 50 \mu \mathrm{l} ; \mathrm{c}$, $75 \mu 1 ; n$, Negative, s, Streptomycin).

Table 2. Antibacterial activity of leaf extracts of C. religiosum.

\begin{tabular}{|c|c|c|c|c|c|c|c|c|c|c|c|}
\hline \multirow{4}{*}{$\begin{array}{l}\text { Pathogens } \\
\text { used }\end{array}$} & \multicolumn{9}{|c|}{ Plant extract } & \multirow{4}{*}{$\begin{array}{l}\text { Negative } \\
\text { control }\end{array}$} & \multirow{4}{*}{$\begin{array}{l}\text { Standard } \\
10 \mathrm{mcg}\end{array}$} \\
\hline & \multicolumn{9}{|c|}{ Zone of Inhibition measured in $\mathbf{m m}$} & & \\
\hline & \multicolumn{3}{|c|}{ CHL } & \multicolumn{3}{|c|}{ EA } & \multicolumn{3}{|c|}{ METH } & & \\
\hline & 2 & $50 \mathrm{mcg}$ & $75 n$ & $25 \mathrm{mcg}$ & $50 \mathrm{mcg}$ & g & $\mathrm{g}$ & & & & \\
\hline B. su & $00 \pm 0.00$ & $00 \pm 0$ & $00 \pm 0.00$ & $12 \pm 0.14$ & $13 \pm$ & $17 \pm 0.24$ & $00 \pm 0.00$ & .00 & & & 25 \\
\hline S. aureus & $00 \pm 0.00$ & $00 \pm 0.00$ & $07 \pm 0.83$ & $0 \pm 0.38$ & $11 \pm 0.08$ & $14 \pm 0.10$ & $00 \pm 0.00$ & .00 & & 00 & .29 \\
\hline P. aeruginosa & $00 \pm 0.00$ & $00 \pm 0.00$ & $00 \pm 0.00$ & $08 \pm 0.32$ & $13 \pm 0.28$ & $23 \pm 0.35$ & $00 \pm 0.00$ & $00 \pm 0.00$ & $00 \pm$ & $00 \pm$ & $26 \pm 0.34$ \\
\hline E. coli & $00 \pm 0.00$ & $00 \pm 0.00$ & $06 \pm 0.71$ & $12 \pm 0.19$ & $14 \pm 0.14$ & $26 \pm 0.27$ & $00 \pm 0.00$ & $06 \pm 0.87$ & $09 \pm 0.47$ & $00 \pm 0.00$ & $30 \pm 0.42$ \\
\hline B. cereus & $00 \pm 0.00$ & $00 \pm 0.00$ & $08 \pm 0.32$ & $11 \pm 0.23$ & $13 \pm 0.20$ & $18 \pm 0.43$ & $00 \pm 0.00$ & $00 \pm 0.00$ & $07 \pm 0.54$ & $00 \pm 0.00$ & $24 \pm 0.21$ \\
\hline
\end{tabular}

Note: Values are means of three independent replicates \pm standard error. CHL: Chloroform extracts, EA: Ethyl acetate extracts, METH: Methanol extracts, Negative control: Respective solvents and Standard: Streptomycin (for comparative study, the maximum activity given extracts standard values are mentioned in the table).

DPPH Free radical scavenging activity

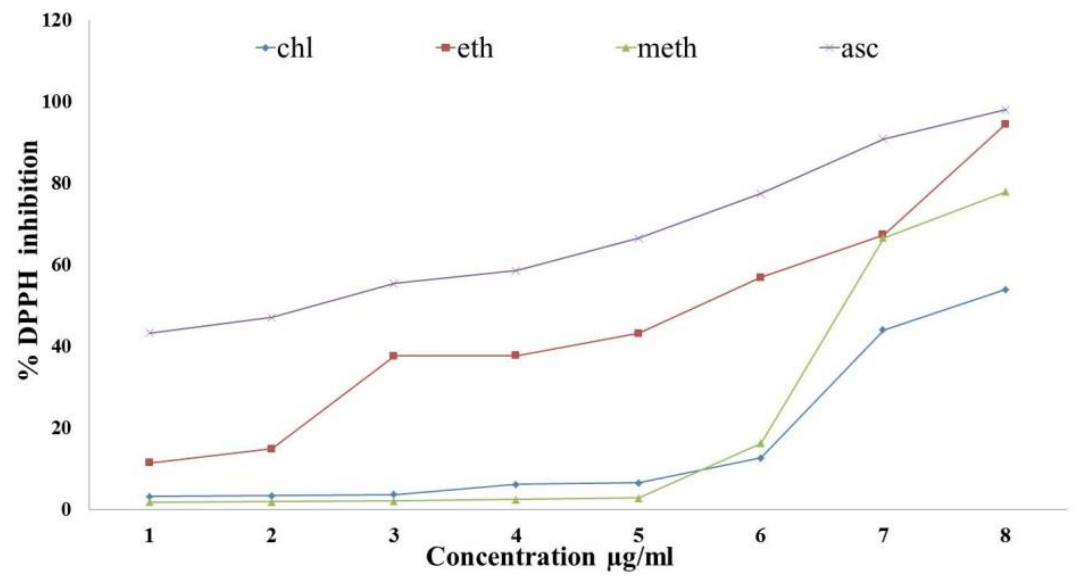

Figure 2. Antioxidant activity of Cochlospermum religiosum leaf extracts by DPPH Scavenging method. 
Medicinal plants known to possess natural antioxidants which preventing the oxidative stress. The free radical scavenging activity of different crude solvent extracts of $C$. religiousum was studied and the results revealed that both chloroform and ethyl acetate extract showed excellent antioxidant activity when compared to methanol extracts and there was complete discoloration of purple colored solution into yellow color solution in chloroform and ethyl acetate, extract of leaf. The degree of discoloration by plant sample was recorded and $\mathrm{IC}_{50}$ was calculated and the results are graphically represented (Fig. 2).

\section{Total phenolic content}

The antioxidant activity of the most of the green and herbaceous plants crude extracts is often allied with phenolic substances hence, they constitute together will make major group of compounds is known as primary antioxidants which are easily react with active oxygen free radicals. Total phenolic content was measured according to Folin - Ciocalteu method with all the three extracts. The results showed that all the extracts of leaf samples used for the present investigation contain considerable amount of polyphenols. The methanol extract was found to contain the highest amount of phenols (35.4\%) when calculated with the standard Gallic acid curve (Fig. 3).

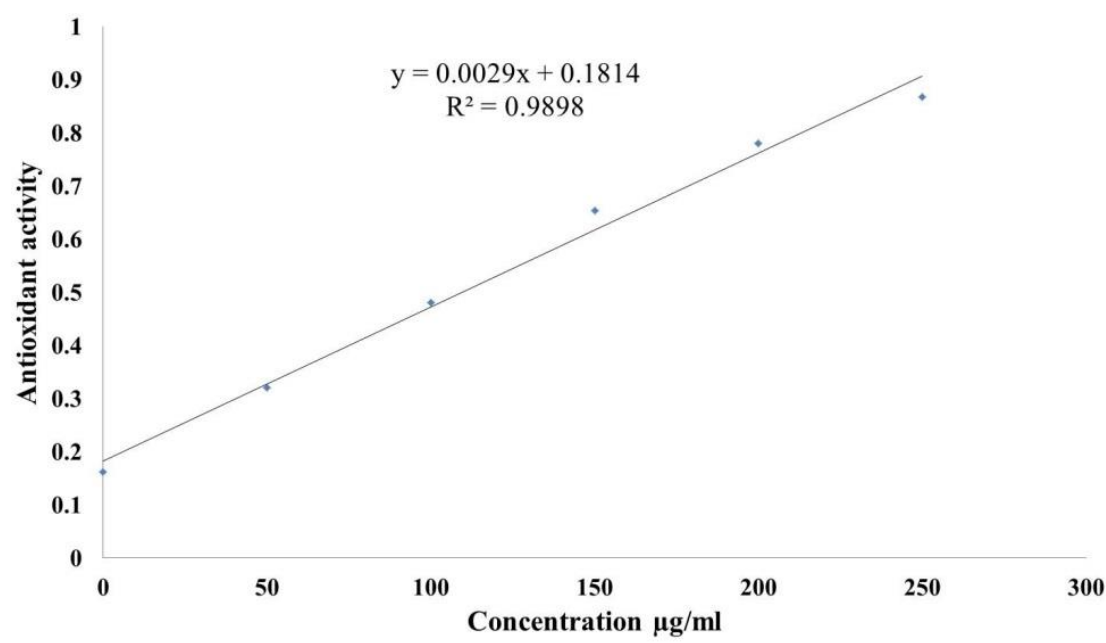

Figure 3. Antioxidant activity of Cochlospermum religiosum leaf extracts by Total phenolic method (Gallic acid curve).

Total antioxidant capacity by Phospho-molybdenum method

Total antioxidant capacity of leaf extract of $C$. religiosum was evaluated by phospho - molybdenum method and was expressed as Gallic acid as a standard per gram of plant extract. Total antioxidant capacity leaf extract of $C$. religiosum was calculated using the standard curve of Gallic acid $(y=0.0428 x+0.2391)$. Among all the three extract of plant, the methanol was found to possess the highest total antioxidant capacity of $4.5 \%$ and antioxidant capacity of Gallic acid has been used as a reference standard from which plant extracts which possess potential antioxidant activity are comparable with standard graph (Fig. 4) plotted against tested samples.

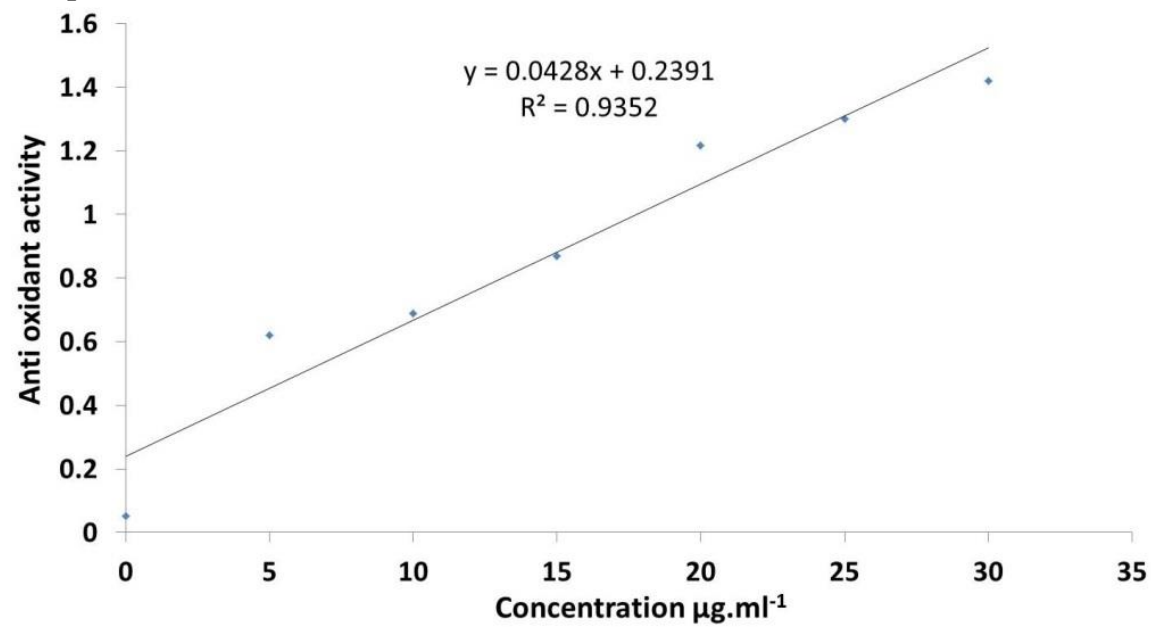

Figure 4. Antioxidant activity of Cochlospermum religiosum leaf extracts by Phospho-molybdenum method (Gallic acid curve). 


\section{DISCUSSION}

It was understood from the present study that the extracts of $C$. religiosum contain many phytochemicals as revealed by biochemical tests. Most of the plants which possess vast number of secondary metabolites some times which act as defense mechanism for external invaders such kind of phytochemical constituents produced by them self they played major role in defense system. In this study, the phytochemical analysis of the methanol extract of the $C$. religiosum showed the presence of more number of secondary metabolites like terpenoids, saponins, phenolics, alkaloids, glycosides comparable with that of other solvent extracts. Likewise, Cooper et al. (2006) was also reported presence of more group of phytochemical diversity which gives synergic effects in many biological applications.

Further, each extracts were subjected to explore for their antibacterial activity against some gram positive and gram negative bacterial strains with various range of concentrations. The outcome of the antibacterial assay revealed that there is an increasing the concentration of the extracts will leads to inhibit the growth of bacteria and the same was compared with standard antibiotic drug. In concurrence to this, Shakeri et al. (2012) in Anabasis aphylla also reported increased zone of inhibition with increasing concentration of extracts. The antioxidant activity of the extracts and is measured by the ability to scavenge DPPH free radicals, is observed in figure 2. The percentage inhibition of free radical by $C$. relgiosum extracts significantly reduced color of the DPPH reagent from purple to yellow. The highest antioxidant activity of was observed by the Ethyl acetate followed by Chloroform extracts. In corroborated with findings of Marzouk et al. (2006) stated that Tecoma stans has a good antioxidant activity in various extracts of aerial parts showed significant antioxidant activity as measured by DPPH as a scavenging reagent. Likewise, Torane et al. (2011) also reported, the antioxidant activity of Tecoma stans ethyl acetate extracts is higher than methanol and acetone extract. Based on antioxidant activities, the total phenolic content and phospho- molybdenum method was also conducted and the results are moderate for $C$. relgiosum. Most of the previous researches have also been reported, majority of the plant compounds responsible for antioxidant activity are due to the presence of polyphenols, similar way, the verdicts of our result shows the phenolic content is slightly higher than some other medicinal plants. The antioxidant activity of phenolic compounds is due to their redox property which plays an important role in absorbing and neutralizing free radicals, quenching singlet and triplet oxygen and a metal chelation potential. The results of the present study are agreement with that of Abdelwahab et al. (2009).

\section{CONCLUSION}

The present study summarizes that $C$. religiosum is a good source of various metabolites like steroids, flavonoids, triterpenoids, glycosides, tannins, saponins, resins, alkaloids and carbohydrates. Ethyl acetate leaf extract of the plant showed effective antibacterial activity against all the tested bacterial pathogens. The methanol extract of leaf showed excellent radical scavenging activity which was significantly comparable to free radical scavenging activity of ascorbic acid. The finding of this study suggests that the leaves of this plant could be a potential source of natural antioxidant. Further investigation on the isolation and characterization is, however, to be required.

\section{ACKNOWLEDGEMENTS}

The authors are thankful to the University of Mysore, Mysore for providing laboratory facility through Institution of Excellence (IOE) and DST-FIST in the botany department.

\section{REFERENCES}

Abdelwahab SI, Abdul AB, Elhassan MM, Mohan S, Al-Zubairi AS \& Mariod AA (2009) Antimicrobial and free radical scavenging activities of dichloromethane extract of Goniothalamus umbrosus. International Journal of Tropical Medicine 4: 32-36.

Abdulwahab NZ, Shahar S, Abdullah-Sani H, Pihie AH \& Ibrahim N (2011) Antioxidant, antibacterial and antiviral properties of Goniothalamus umbrosus leaves methanolic extract. African Journal of Microbiology Research 5: 3138-3143.

Chlopicka J, Pasko P, Gorinstein S, Jedryas A \& Zagrodzki P (2012) Total phenolic and total flavonoid content, antioxidant activity and sensory evaluation of pseudocereal bread. LWT -Food Science Technology 46: 548555.

Cooper J, Niggli U \& Leifert C (2006) Handbook of organic food safety and quality. Abington Hall, Elsevier. 
Cragg GM \& Newman DJ (2001) Natural product drug discovery in the next millennium. Pharmaceutical Biology 39(1): 8-17.

Fabricant DS \& Farnsworth NR (2001) The value of plants used in traditional medicine for drug discovery. Environmental Health Perspectives 109 (1): 69-76.

Gamble JS \& Fischer CEC (1935) Flora of the Presidency of Madras. West, Newman and Adlard, London.

Harborne JB (1973) Phytochemical methods. Chapman and hall Ltd. London, pp. 49-188.

Lobo V, Patil A, Phatak A \& Chandra N (2010) Free radicals, antioxidants and functional foods: Impact on human health. Pharmacognosy Reviews 4(8): 118.

Mahendra C, Manasa G, Murali M, Amruthesh KN, Sudarshana MS \& Lingaraju DP (2016) Antibacterial and antioxidant properties of Argyria osyrensis. Annals of Phytomedicine 5(1): 110-115.

Maizura M, Aminah A \& Wanaida WM (2011) Total phenolic content and antioxidant activity of kesum, ginger and turmeric extract. International Food Research Journal 18: 529-534.

Marzouk M, Gamal-Eldeen A, Mohamed M \& El Sayed M (2006) Anti-proliferative and antioxidant constituents from Tecoma stans. Zeitschrift Naturforsch-C 61(11-12): 783-791.

Motaleb MA (2011) Selected medicinal plants of Chittagong hill tracts. International union of conservation of nature and natural resources. pp. 1-3.

Motalleb G, Hanachi P, Kua SH, Fauziah O \& Asman R (2005) Evaluation of phenoilc content and antioxidant activity in Berberis Fruit extract. Journal of Biological Sciences 5(5): 648-653.

Pandhure N, Prasad P \& Biradar SR (2013) Micropropagation studies in C. religiousum (Linn). Journal of Medicinal Plant Research 2(6): 263-270.

Sasikala A, Lingarao M \& Savithramma N (2013) Quantification of primary and secondary metabolites from leaves and stem, bark of Cochlospermum religiosum. International Research Journal of Pharmacy 4(8): 228-231.

Shah P, Modi HA, Shukla MD \& Lahiri SK (2014) Preliminary phytochemical analysis and antibacterial activity of Ganoderma lucidum collected from dang district of Gujarat, India. International Journal of Current Microbiology Applied Sciences 3(3): 246-255.

Shakeri1 A, Hazeri N, Vlizadeh J, Ghasemi A \& Tavallaei FZ (2012) Phytochemical screening, Antimicrobial and Antioxidant activities of Anabasis aphylla L. Extracts. Journal of Science and Research 34: 71-78.

Torane RC, Kamble GS, Adsul VB, Shendkar CD \& Deshpande NR (2011) Antioxidant Activity of Aerial Parts of Tecoma stans. International Journal of Chemical Sciences 2: 130-132. 